The applicability of using different energy levels in CT imaging for differentiation or identification of dental restorative materials

Kutschy, Josef M ; Ampanozi, Garyfalia ; Berger, Nicole ; Ruder, Thomas D ; Thali, Michael J ; Ebert, Lars C

DOI: https://doi.org/10.1007/s12024-014-9595-y

Posted at the Zurich Open Repository and Archive, University of Zurich

ZORA URL: https://doi.org/10.5167/uzh-99213

Journal Article

Published Version

Originally published at:

Kutschy, Josef M; Ampanozi, Garyfalia; Berger, Nicole; Ruder, Thomas D; Thali, Michael J; Ebert, Lars C (2014). The applicability of using different energy levels in CT imaging for differentiation or identification of dental restorative materials. Forensic Science, Medicine, and Pathology, 10(4):543-549. DOI: https://doi.org/10.1007/s12024-014-9595-y 


\title{
The applicability of using different energy levels in CT imaging for differentiation or identification of dental restorative materials
}

\author{
Josef M. Kutschy • Garyfalia Ampanozi • Nicole Berger • \\ Thomas D. Ruder · Michael J. Thali • Lars C. Ebert
}

Accepted: 12 July 2014/Published online: 13 August 2014

(C) Springer Science+Business Media New York 2014

\begin{abstract}
Purpose The goal of this study was to investigate whether different computed tomography (CT) energy levels could supply additional information for the differentiation of dental materials for forensic investigations.

Methods Nine different commonly used restorative dental materials were investigated in this study. A total of 75 human third molars were filled with the restorative dental materials and then scanned using the forensic reference phantom in singlesource mode. The mean Hounsfield unit values and standard deviations (SDs) of each material were calculated at 120, 80 and $140 \mathrm{kVp}$.

Results Most of the dental materials could be differentiated at $120 \mathrm{kVp}$. We found that greater X-ray density of a material resulted in higher SDs and that the material volume could influence the measurements.

Conclusion Differentiation of dental materials in CT was possible in many cases using single-energy CT scans at $120 \mathrm{kVp}$. Because of the number of dental restorative
\end{abstract}

J. M. Kutschy · G. Ampanozi · N. Berger ·

T. D. Ruder - M. J. Thali · L. C. Ebert $(\bowtie)$

Department of Forensic Medicine and Imaging, Institute of Forensic Medicine, University of Zürich, Winterthurerstrasse 190/52, 8057 Zurich, Switzerland

e-mail: lars.ebert@virtopsy.com; lars.ebert@irm.uzh.ch

N. Berger

Institute of Diagnostic and Interventional Radiology, University

Hospital of Zürich, Raemistrasse 100, 8091 Zurich, Switzerland

T. D. Ruder

Institute of Diagnostic, Interventional, and Pediatric Radiology, University Hospital Bern, Freiburgstrasse, 3010 Bern,

Switzerland materials available and scanner and scan parameter dependence, as well as the CT imaging artifacts, the identification (in contrast to differentiation) was problematic.

Keywords Forensic radiology - Forensic identification · Dental materials - Single-source dual-energy CT .

Dual-source dual-energy CT · Virtopsy

\section{Introduction}

Determining a deceased person's identity is an important task in many forensic investigations. The gold standard for dental identification is the visual dental record and the comparison of any ante-mortem and postmortem radiographs [1,2]. Visual analysis of dental fillings will become increasingly difficult for forensic odontologists in the future because gold and amalgam fillings will become less prevalent, and new composite and ceramic fillings, which imitate natural dental tissue perfectly, will increasingly appear [1]. These new generation filling materials can appear identical to a tooth in color and brilliance; therefore, it will be increasingly difficult to distinguish fillings from natural dental tissue. This challenge could be overcome using medical imaging modalities. In events with mass casualties, radiological imaging has already played an important role in victim identification and has proven to be a valuable alternative to fingerprinting and DNA identification $[3,4]$. With the routine use of computed tomography (CT) imaging in forensic investigations in blinded studies, new identification methods are possible and have already been established [5]. With the help of cranial CT data, it has become possible to reconstruct and simulate most antemortem radiographs for comparison [3]. The X-ray 
comparison includes the bony specification of the jaw, mandibular and maxillary sinuses, any pathological changes, presence of teeth, and shapes of the roots and dental restorations [2]. In charred bodies, postmortem CT provides noninvasive documentation of fragile and brittle teeth [2].

Not only can the size and location of the dental fillings be used for forensic identification; the composition of the dental material can also be of interest. However, a precise differentiation of dental materials using X-ray attenuation, measured in Hounsfield units (HU), can be challenging because many dental materials show similar CT numbers, or their CT numbers overlap with those of teeth [1]. Technical innovations, such as dual-energy CT (DECT), could help to solve these issues.

Different materials have different X-ray attenuation for different X-ray energy levels, thus, resulting in different HU [6]. This phenomenon could be utilized to gain additional information for material differentiation, and it is the basis for DECT. This novel CT generation allows for better imaging quality, and it might provide more information about tissue composition or the behavior of a substance at different energy levels compared to common CT [6]. The potential of DECT for material differentiation was previously investigated by Ruder et al. [7]. The authors described the differentiation of frequently encountered foreign materials in human bodies using DECT. In addition, they suggested that it was also possible to perform two separate scans on single-energy CT to obtain results similar to those obtained with DECT, a technique that has potential value for the differentiation of dental restoration materials.
Based on this work, we investigated the behavior of different commonly used dental fillings at different energy levels, as well as how this information could be used for the differentiation of dental materials.

\section{Materials and methods}

Nine different commonly used restorative dental materials were investigated in this study. To have a representative variety of samples, we investigated 3 temporary, 3 permanent and 3 laboratory-side materials (Table 1). A total of 75 human third molars, which were collected by a dentist after an indicated extraction, were prepared with different sizes of cavities. For every tooth, only one cavity was prepared, and the cavity size increased throughout the series of teeth. Ten teeth were filled with the same material, except for the lab-side materials, of which only five teeth were prepared for each material because of the high costs of these materials. This preparation resulted in 75 restorative fillings of different known materials (Fig. 1). To determine the filling volume exactly, the teeth were weighed after preparing the cavities and again after filling the cavities. Therefore, the weight of each filling could be determined, and with the known density of each material, as provided by the manufacturer, the volume of each filling was calculated (Table 1).

The roots of the teeth were embedded in Coltoflax (Coltène/Whaledent AG, Alstätten, Sankt Gallen, Switzerland), a silicon-based impression material that creates no artifacts on CT scans and that is used as a surrogate for

Table 1 Nine different commonly used investigated dental materials

\begin{tabular}{|c|c|c|c|}
\hline Trade name & Specification & Supplier & $\begin{array}{l}\text { Density } \\
\left(\mathrm{g} / \mathrm{cm}^{3}\right)\end{array}$ \\
\hline \multicolumn{4}{|l|}{ Temporary filling materials } \\
\hline Ketac Fil Plus Aplicap (Ketac) & Glas Inomer Filling Material & 3 M Deutschland GmbH, Neuss, Germany & 2.375 \\
\hline Coltosol F (Coltosol) & Zinc oxide/zinc sulfate based cement & Coltène/Whaladent AG, Alstätten, Switzerland & 2.4 \\
\hline Cavit G (Cavit) & Zinc oxide/calzium sulfate based cement & 3M Deutschland GmbH, Neuss, Germany & 2.8 \\
\hline \multicolumn{4}{|l|}{ Permanent filling materials } \\
\hline Cm Tetric EvoFlow (Flow) & $\begin{array}{l}\text { Flowable, light-curing, nano-hybrid } \\
\text { composite }\end{array}$ & Ivoclar/Vivadent AG, Schaan, Lichtenstein & 1.78 \\
\hline $\begin{array}{l}\text { Cm Tetric EvoCeram } \\
\text { (Composite) }\end{array}$ & Light-curing, nano-hybrid composite & Ivoclar/Vivadent AG, Schaan, Lichtenstein & 2.1 \\
\hline Oralloy Magicap S (Amalgam) & Non-Gamma-2 amalgam & Coltène/Whaladent AG, Altstätten, Switzerland & 13.55 \\
\hline \multicolumn{4}{|l|}{ Lab side materials } \\
\hline Unoral Bio 1 (Gold) & Gold alloy & Unor AG, Schlieren, Switzerland & 15.4 \\
\hline IPS e.max Press (E.max) & Lithium disilicate glass-ceramics & Ivoclar/Vivadent AG, Schaan, Lichtenstein & 2.5 \\
\hline Zirkonoxid (zirconium oxide) & Yttrium stabilized zirconium oxide & $\begin{array}{l}\text { Metaux Precieux Dental GmbH, Stuttgart, } \\
\text { Germany }\end{array}$ & 6.05 \\
\hline 75 Restorative fillings & & & \\
\hline
\end{tabular}




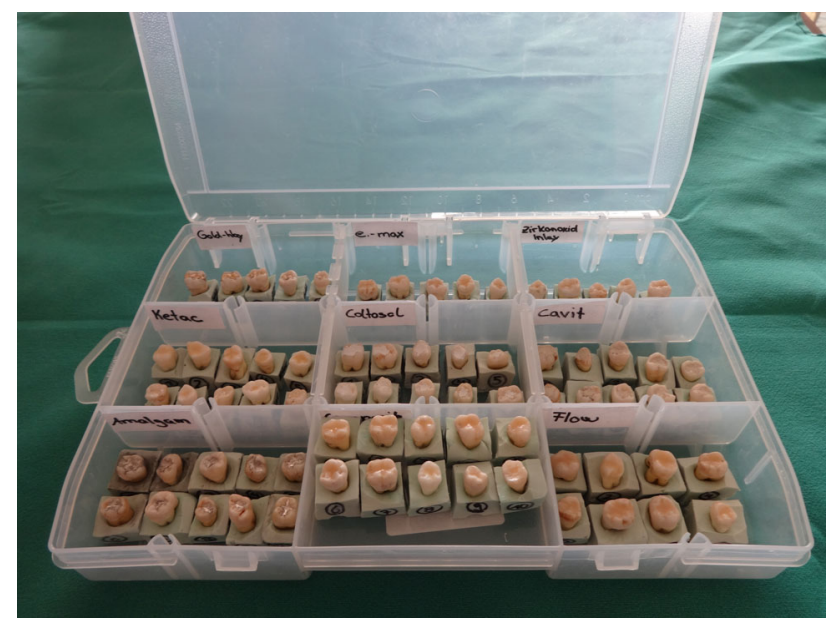

Fig. 1 Seventy-five human third molars were prepared and filled with different filling materials

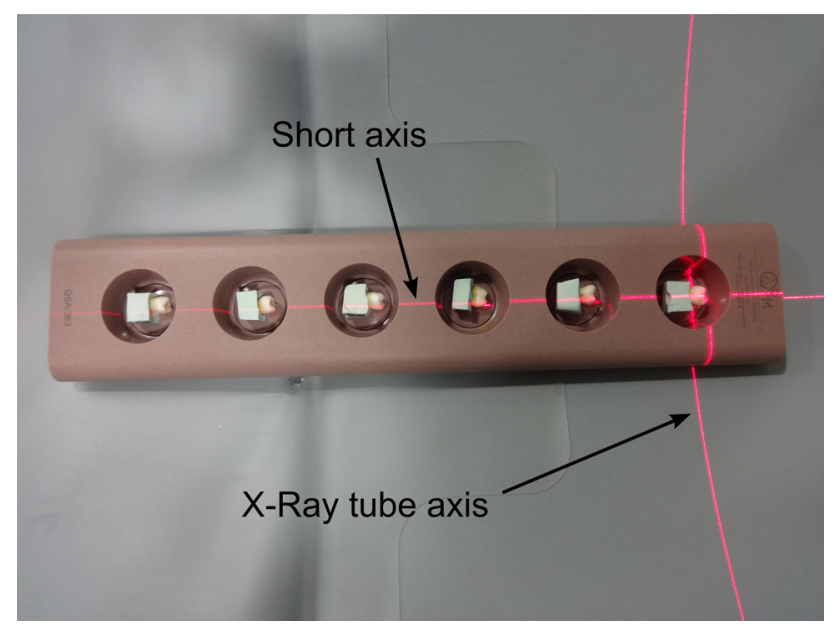

Fig. 2 Teeth in the FRP before scanning; the short axis of the teeth is orthogonal to the X-ray tube

bone in research using CT [8]. To ensure scanning quality, we scanned the teeth using a forensic reference phantom (FRP) (QRM GmbH, Möhrensdorf, Germany) [9]. All teeth were positioned in the FRP with the long axis of the tooth orthogonal to the X-ray beam and simulating the natural position of the teeth during postmortem $\mathrm{CT}$ scanning. We refrained from using artificial saliva (Fig. 2).

\section{Scanning parameters and measurements}

The scans were obtained using a dual-source, 128-slice multi-detector row CT scanner (Somatom Definition Flash, Siemens AG, Healthcare Sector, Erlangen, Germany) in single-source mode, to facilitate reconstruction with as extended a $\mathrm{CT}$ scale as possible.

The teeth were scanned at 80,120 , and $140 \mathrm{kVp}$ with $500 \mathrm{~mA}$.

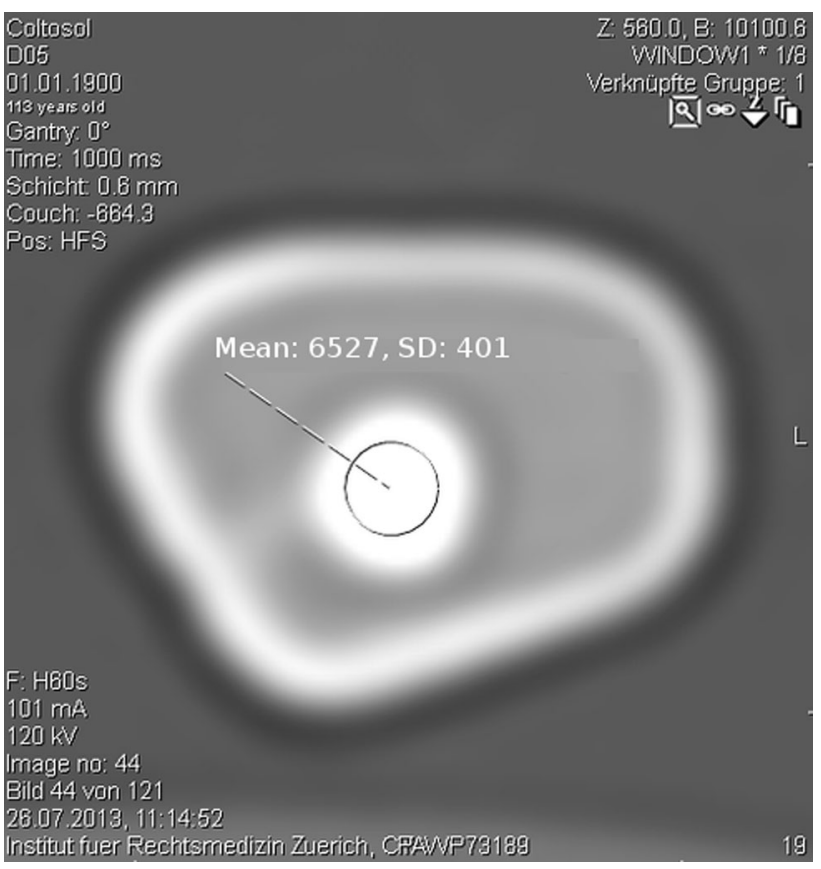

Fig. 3 HU measurement with an ROI tool placed in the middle of the filling material. Coltosol $\mathrm{F}$ filling at $120 \mathrm{kVp}$, with an extended CT scale (screenshot manipulated for English translation)

All scans were performed with a collimation of $0.6 \mathrm{~mm}$ and a rotation time of $1 \mathrm{~s}$. The CT image reconstruction was performed using bone-weighted tissue kernels and an extended CT scale. The extended CT scale extended the scale by a factor for 10 , thus allowing for materials with densities greater than 3,071 $\mathrm{HU}$ to be measured at the cost of Hounsfield resolution.

All measurements were obtained by a radiologist and a dentist using a pictures archiving and communication system (PACS) workstation (IDS7, Sectra, Linköping, Sweden). The HU were measured using a circular region of interest (ROI) tool. The ROIs were placed manually in the center of the filling materials to avoid measurement artifacts due to partial volume effects (Fig. 3). The ROI that was chosen was sufficiently large to ensure that each ROI included several voxels. We performed one measurement on every scan slice of the filling material; therefore, the actual number of measurements per tooth varied. The measurements were repeated for different tube voltages. In total, we obtained between 25 and 55 measurements per filling material, for a total of 1,168 measurements. In addition, we measured the $\mathrm{HU}$ of the dentin and enamel once for every tooth. Because measuring with HU yields high inter-rater reliability, we refrained from having another person repeat the measurements [10]. All values were stored in a Microsoft Excel table (Microsoft Corp., Redmond, WA, USA). 


\section{Statistics}

For statistical analysis, we used the SPSS software, version 20.0.0 (IBM, Armonk, NY, NY, USA), and the GraphPad Prism software, version 6.04 (GraphPad Software, Inc., La Jolla, CA, USA).

The mean HU values and standard deviations (SD) for each of the tested materials, as well as for enamel and dentin, were calculated at 120,80 , and $140 \mathrm{kVp}$. To identify whether the tested materials can be differentiated using Hounsfield values, we used one-way analysis of variance (ANOVA) with Tukey's multiple comparison test as a post hoc test.

Furthermore, the HU measurements of each material were plotted for differences. Because CT scanners are calibrated to work optimally on human tissue and, therefore, on lower Hounsfield values, we hypothesized that the materials with higher Hounsfield values would have greater standard deviations of the measurements. Because the data were not normally distributed, we calculated Spearman's correlation coefficients. To identify the correlations

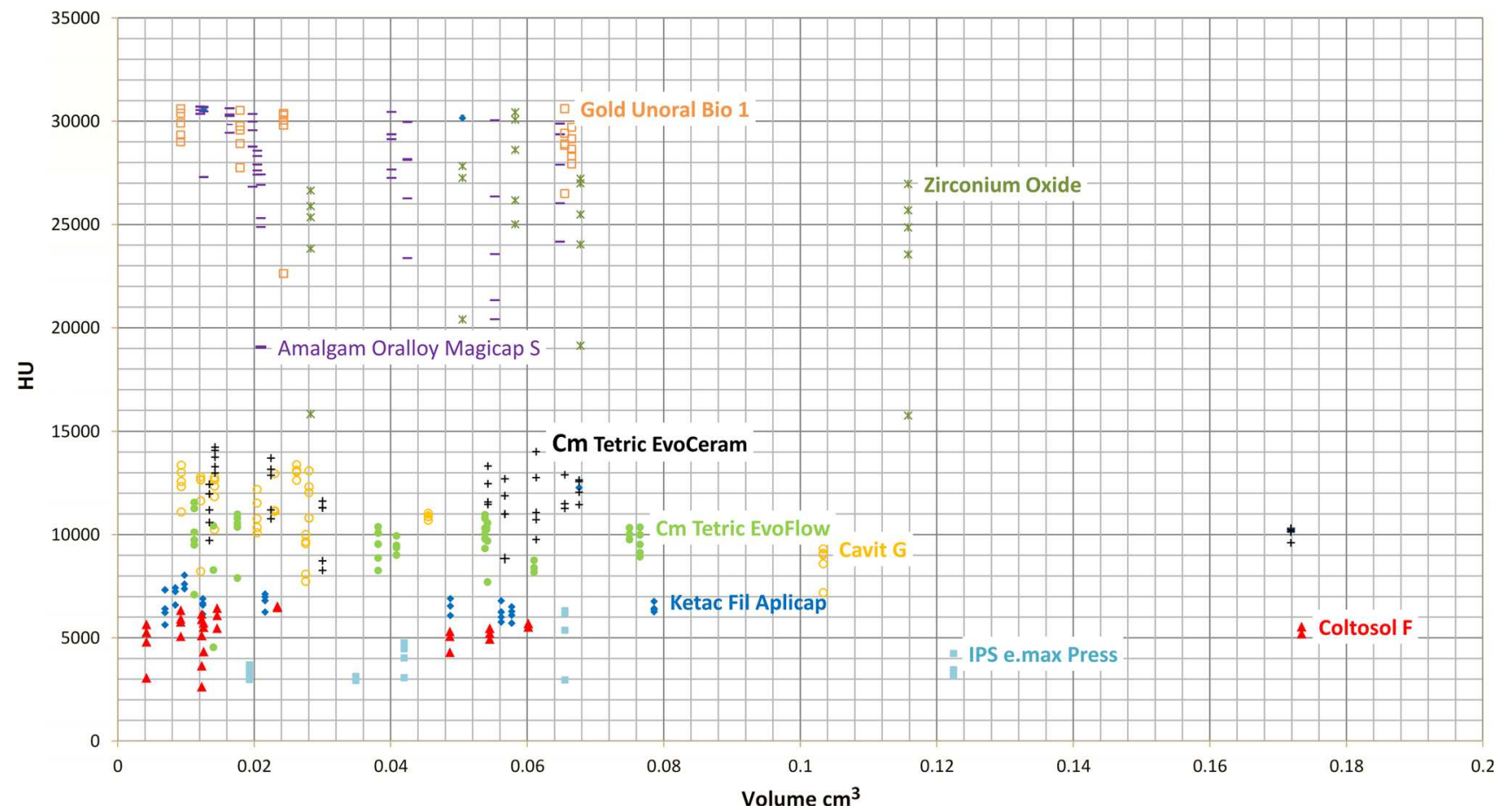

Fig. 4 The CT numbers of each tested material at different filling volumes

Table 2 The mean HU values of the different dental materials at 120,80 and $140 \mathrm{kVp}$

\begin{tabular}{llll}
\hline Material & $120 \mathrm{kVp} / \mathrm{SD}$ & $80 \mathrm{kVp} / \mathrm{SD}$ & $140 \mathrm{kVp} / \mathrm{SD}$ \\
\hline Ketac Fil Plus Aplicap & $6,576 / 567$ & $9,360 / 1,235$ & $5,836 / 503$ \\
Coltosol F & $5,467 / 811$ & $8,176 / 1,207$ & $4,959 / 537$ \\
Cavit G & $11,193 / 1,633$ & $16,544 / 2,825$ & $9,554 / 1,402$ \\
Cm Tetric EvoFlow & $9,593 / 1,175$ & $11,938 / 1,483$ & $8,519 / 1,174$ \\
Cm Tetric EvoCeram & $11,705 / 1,485$ & $15,242 / 2,134$ & $10,120 / 1,348$ \\
Oralloy Magicap S & $28,021 / 2,816$ & $27,136 / 4,870$ & $28,775 / 2,510$ \\
Unoral Bio 1 & $29,080 / 1,677$ & $28,508 / 2,209$ & $29,270 / 1,669$ \\
Zirconium oxide & $25,335 / 3,983$ & $26,994 / 4,413$ & $23,900 / 3,843$ \\
IPS e.max Press & $3,927 / 1,086$ & $5,025 / 1,179$ & $3,623 / 1,143$ \\
Dentin & $2,209 / 513$ & $3,015 / 780$ & $2,143 / 673$ \\
Enamel & $4,188 / 556$ & $5,760 / 955$ & $3,775 / 829$ \\
\hline
\end{tabular}


between the HU values and material volumes, we used Pearson's correlation test.

\section{Results}

The sizes of the examined filling materials were between 0.004 and $0.173 \mathrm{~cm}^{3}$. Ketac, Cavit, and amalgam showed significant correlations between the measured $\mathrm{HU}$ values and material volumes $(p<0.01)$ (Fig. 4).

The mean HU measurements for enamel were at 4,188 HU at $120 \mathrm{kVp}(\mathrm{SD}, 556), 5,760 \mathrm{HU}$ at $80 \mathrm{kVp}(\mathrm{SD}, 955)$ and $3,775 \mathrm{HU}$ at $140 \mathrm{kVp}(\mathrm{SD}, 829)$. The mean HU measurements for dentin were 2,209 $\mathrm{HU}$ at $120 \mathrm{kVp}$ (SD, 513), 3,015 $\mathrm{HU}$ at $80 \mathrm{kVp}$ (SD, 780) and at 2,143 $\mathrm{HU}$ at $140 \mathrm{kVp}$ (SD, 673). Table 2 shows the mean HUs of the 9 investigated dental materials and both enamel and dentin at 120,80 and $140 \mathrm{kVp}$. E.max was the material with the lowest Hounsfield values. The HU range of E.max was between the HU measurements of enamel and dentin, with the exception of the $\mathrm{HU}$ values for E.max at $120 \mathrm{kVp}$. In this case, the HU range of dentin and E.max overlapped. The highest HU values were represented by the two metal fillings: amalgam and gold.

ANOVA showed significant differences among the mean Hounsfield values of the different filling materials $(p<0.05)$. Table 3 summarizes 120,80 , and $140 \mathrm{kVp}$ based on whether the HU differences were shown to be statistically significant using Tukey's multiple comparisons test. For most of the materials, differentiation was possible at $120 \mathrm{kVp}$. Three combinations (i.e., amalgam and gold, Cavit and composite, and Ketac and Coltosol) could not be distinguished at 80,120 , or $140 \mathrm{kVp}$, respectively. In addition, amalgam and E.max, as well as gold and E.max, showed similar HUs at $80 \mathrm{kVp}$ but not at 120 or $140 \mathrm{kVp}$. These results are shown in Table 3.

When testing the correlation of the material density with the standard deviation, we found that greater X-ray density of a material resulted in higher standard deviations (Spearman's rho $=0.730, p<0.01$ ).

\section{Discussion}

The aim of this article was to assess whether and how different energy levels in CT imaging could be used to differentiate or to identify dental filling materials. Due to the vast amount of different dental filling materials, we chose a variety of materials that best covered the range of available materials. Most of the tested materials could be differentiated at $120 \mathrm{kVp}$. Scans with 80 and $140 \mathrm{kVp}$ did not provide any additional information.
Table 3 Differentiation between dental materials at 120, 80 and $140 \mathrm{kVp}$, for all material permutations

\begin{tabular}{|c|c|c|c|}
\hline Material $1 /$ material 2 & $120 \mathrm{kV}$ & $80 \mathrm{kV}$ & $140 \mathrm{kV}$ \\
\hline Ketac Fil Plus Aplicap/Coltosol F & ns & ns & ns \\
\hline Ketac Fil Plus Aplicap/Cavit G & $\mathrm{s}$ & $\mathrm{s}$ & $\mathrm{s}$ \\
\hline $\begin{array}{l}\text { Ketac Fil Plus Aplicap/Cm Tetric } \\
\text { EvoFlow }\end{array}$ & $\mathrm{s}$ & $\mathrm{s}$ & $\mathrm{s}$ \\
\hline $\begin{array}{l}\text { Ketac Fil Plus Aplicap/Cm Tetric } \\
\text { EvoCeram }\end{array}$ & $\mathrm{s}$ & $\mathrm{s}$ & $\mathrm{s}$ \\
\hline $\begin{array}{l}\text { Ketac Fil Plus Aplicap/Amalgam } \\
\text { Oralloy Magicap S }\end{array}$ & $\mathrm{s}$ & $\mathrm{s}$ & $\mathrm{s}$ \\
\hline $\begin{array}{l}\text { Ketac Fil Plus Aplicap/ } \\
\text { Gold Unoral Bio } 1\end{array}$ & $\mathrm{~s}$ & $\mathrm{~s}$ & $\mathrm{~s}$ \\
\hline Ketac Fil Plus Aplicap/Zirconium oxide & $\mathrm{s}$ & $\mathrm{s}$ & $\mathrm{s}$ \\
\hline Ketac Fil Plus Aplicap/IPS e.max Press & $\mathrm{s}$ & $\mathrm{s}$ & $\mathrm{s}$ \\
\hline Coltosol F/Cavit G & $\mathrm{s}$ & $\mathrm{s}$ & $\mathrm{s}$ \\
\hline Coltosol F/Cm Tetric EvoFlow & $\mathrm{s}$ & $\mathrm{s}$ & $\mathrm{s}$ \\
\hline Coltosol F/Cm Tetric EvoCeram & $\mathrm{s}$ & $\mathrm{s}$ & $\mathrm{s}$ \\
\hline Coltosol F/Amalgam Oralloy Magicap S & $\mathrm{s}$ & $\mathrm{s}$ & $\mathrm{s}$ \\
\hline Coltosol F/Gold Unoral Bio 1 & $\mathrm{~s}$ & $\mathrm{~s}$ & $\mathrm{~s}$ \\
\hline Coltosol F/Zirconium oxide & $\mathrm{s}$ & $\mathrm{s}$ & $\mathrm{s}$ \\
\hline Coltosol F/IPS e.max Press & $\mathrm{s}$ & $\mathrm{s}$ & $\mathrm{s}$ \\
\hline Cavit G/Cm Tetric EvoFlow & $\mathrm{s}$ & $\mathrm{s}$ & $\mathrm{s}$ \\
\hline Cavit G/Cm Tetric EvoCeram & ns & ns & ns \\
\hline Cavit G/Amalgam Oralloy Magicap S & $\mathrm{s}$ & $\mathrm{s}$ & $\mathrm{s}$ \\
\hline Cavit G/Gold Unoral Bio 1 & $\mathrm{~s}$ & $\mathrm{~s}$ & $\mathrm{~s}$ \\
\hline Cavit G/Zirconium oxide & $\mathrm{s}$ & $\mathrm{s}$ & $\mathrm{s}$ \\
\hline Cavit G/IPS e.max Press & $\mathrm{s}$ & $\mathrm{s}$ & $\mathrm{s}$ \\
\hline $\begin{array}{l}\text { Cm Tetric EvoFlow/Cm Tetric } \\
\text { EvoCeram }\end{array}$ & $\mathrm{s}$ & $\mathrm{s}$ & $\mathrm{s}$ \\
\hline $\begin{array}{l}\text { Cm Tetric EvoFlow/Amalgam Oralloy } \\
\text { Magicap S }\end{array}$ & $\mathrm{s}$ & $\mathrm{s}$ & $\mathrm{s}$ \\
\hline Cm Tetric EvoFlow/Gold Unoral Bio 1 & $\mathrm{~s}$ & $\mathrm{~s}$ & $\mathrm{~s}$ \\
\hline $\mathrm{Cm}$ Tetric EvoFlow/Zirconium oxide & $\mathrm{s}$ & $\mathrm{s}$ & $\mathrm{s}$ \\
\hline $\mathrm{Cm}$ Tetric EvoFlow/IPS e.max Press & $\mathrm{s}$ & $\mathrm{s}$ & $\mathrm{s}$ \\
\hline $\begin{array}{l}\text { Cm Tetric EvoCeram/Amalgam Oralloy } \\
\text { Magicap S }\end{array}$ & $\mathrm{s}$ & $\mathrm{s}$ & $\mathrm{s}$ \\
\hline Cm Tetric EvoCeram/Gold Unoral Bio 1 & $\mathrm{~s}$ & $\mathrm{~s}$ & $\mathrm{~s}$ \\
\hline Cm Tetric EvoCeram/Zirconium oxide & $\mathrm{s}$ & $\mathrm{s}$ & $\mathrm{s}$ \\
\hline Cm Tetric Evo Ceram/IPS e.max Press & $\mathrm{s}$ & $\mathrm{s}$ & $\mathrm{s}$ \\
\hline $\begin{array}{l}\text { Amalgam Oralloy Magicap S/Gold } \\
\text { Unoral Bio } 1\end{array}$ & ns & ns & $\mathrm{ns}$ \\
\hline $\begin{array}{l}\text { Amalgam Oralloy Magicap S/Zirconium } \\
\text { oxide }\end{array}$ & $\mathrm{s}$ & $\mathrm{s}$ & $\mathrm{s}$ \\
\hline $\begin{array}{l}\text { Amalgam Oralloy magicap S/IPS e.max } \\
\text { Press }\end{array}$ & $\mathrm{s}$ & ns & $\mathrm{s}$ \\
\hline Gold Unoral Bio 1/Zirconium oxide & $\mathrm{s}$ & $\mathrm{s}$ & $\mathrm{s}$ \\
\hline Gold Unoral Bio 1/IPS e.max Press & $\mathrm{s}$ & ns & $\mathrm{s}$ \\
\hline Zirconium oxide/IPS e.max Press & $\mathrm{s}$ & $\mathrm{s}$ & $\mathrm{s}$ \\
\hline
\end{tabular}

$s$ statistically significant difference between HU values; $n s$ no statistically significantly different $\mathrm{HU}$ values 
For forensic purposes, the identification (in contrast to differentiation) of dental materials would be most desirable, but it is nearly impossible for several reasons. To identify dental materials, measuring and comparing to known Hounsfield measurements are not sufficient because the results of the measurements were strongly scanner and scan parameter dependent [10]. In addition, the sheer number of available filling materials from different manufacturers makes material identification impossible. Therefore, the approach suggested by Ruder et al. [9] which involves a reference phantom to scan different suspected materials in a body, appears to be more promising.

In our study, most of the dental materials could be differentiated at $120 \mathrm{kVp}$. The likelihood of correctly differentiating materials was lowest on the $80 \mathrm{kVp}$ scans because of the greater noise and the resulting higher standard deviations of the measurements (Fig. 5). Only three materials could not be distinguished from one another because they had overlapping $\mathrm{HU}$ values for 80,120 , and $140 \mathrm{kVp}$. Jackowski et al. [8] performed a study using DECT (unfortunately, only in single source mode) to differentiate between different dental fillings. The Hounsfield values we measured at $120 \mathrm{kVp}$ differed slightly from those presented in their article, most likely because of the different scan parameters used. In contrast to the study by Jackowski et al. we could differentiate most of the examined materials using an SSSE scan with an extended CT scale at $120 \mathrm{kVp}$. This ability might have been because of the different materials tested, different scanners used, or different approaches in statistical evaluation (mean value vs. ANOVA) [10]. There are two likely reasons why some filling materials could not be differentiated: (1) high-density materials, such as gold and amalgam, have high SDs of their measurements, making differentiation difficult; (2) dental materials often have radiopaque agents, such as barium, strontium, or zinc, added to ensure visibility on dental radiographs by increasing their X-ray attenuation [11]. These additions could lead to similar HUs for dental materials with similar radiopaque additions, which was the case for composite and Cavit, both of which contain barium that increases their radiopacity and results in comparable CT numbers. For the tested materials, DECT did not provide additional information. However, higher energy levels decreased imaging noise and, therefore, the standard deviations of the measured Hounsfield values.

The material volume, even for the small volumes used for dental fillings, could affect the Hounsfield measurements. Dental filling materials tend to have high X-ray attenuation, usually greater than the level that can be measured without an extended CT scale. High-density materials create a variety of artifacts, such as photon starvation or beam hardening. Higher material volumes create more artifacts, thus, influencing the measurements to a greater extent [12].

The number and selection of the investigated dental materials might be criticized. A large variety of dental materials are on the market, making it impossible to include all of them. To include as many different materials as possible, we selected some of the most common dental materials (in Central Europe). In addition, we also selected gold and amalgam fillings because they are still common in postmortem investigations.

Note that CT scanners are not primarily built to scan materials with high $\mathrm{HU}$ values. This results in greater variation in measured values in high-density materials, which explains the problems in differentiating some of the high-density materials, such as gold and amalgam. In addition, such high $\mathrm{X}$-ray densities require image reconstruction using an extended CT scale, which is not available on all CT scanners.

It is tempting to use Hounsfield measurements to identify or differentiate materials because these values appear to be accurate representations of a material's X-ray attenuation. Unfortunately, a variety of parameters influence these measurements. The scanner type and scanning protocols, material volumes, imaging, and reconstruction artifacts, and percentage, as well as the type of fillers and radiopaque
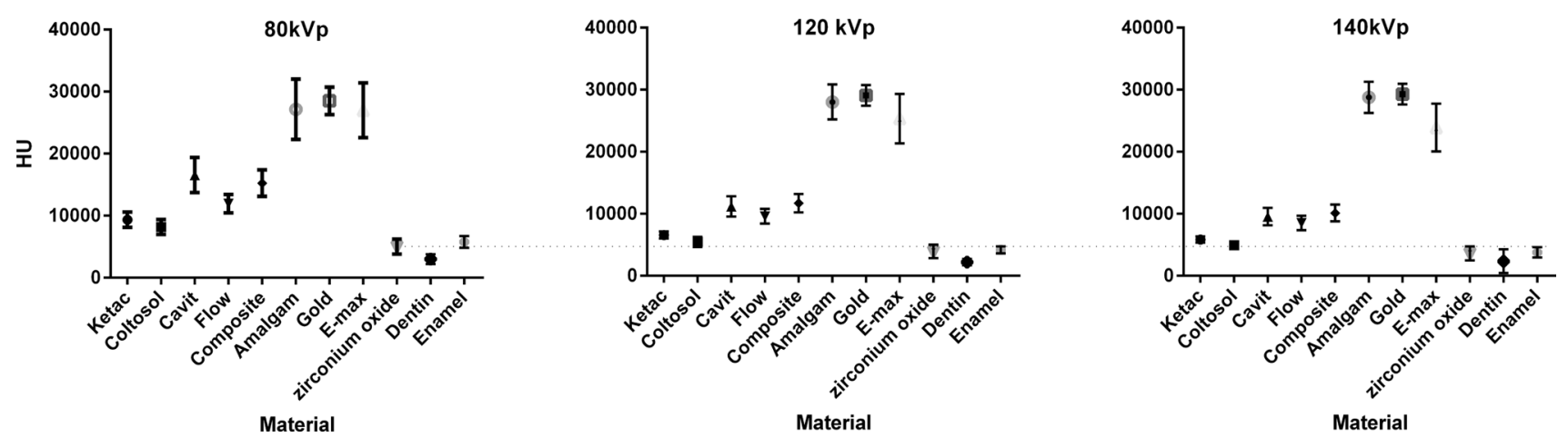

Fig. 5 Measured HU values of different dental materials at different energy levels, with means and SDs 
additives, can all alter Hounsfield measurements and make differentiation difficult and identification impossible, particularly with small material amounts, such as those used for dental materials. Dual-source scans did not provide additional information for the tested materials. In our opinion, the material identification of dental materials using CT imaging is, therefore, not feasible with currently available scanners. Material differentiation can be performed in some instances, but one should be aware of the limitations.

\section{Conclusions}

The results of our study suggested that multiple energy level scans yielded no additional information for the differentiation of dental filling materials than a standard $120 \mathrm{kVp}$ scan. In addition, we showed that the filling volume could affect the Hounsfield measurements for some materials. The measurements of high-density materials had higher SDs, making it more difficult to differentiate between them. To conclude, because of the existing number of dental restorative materials available, scanner and scan parameter dependence of the measurements and a variety of CT imaging artifacts, the identification (in contrast to differentiation) of dental materials is problematic.

\section{Key points}

1. Most of the tested dental materials can be differentiated in CT images at $120 \mathrm{kVp}$, scans with 80 and $140 \mathrm{kVp}$ did not provide additional information.

2. The filling volume can affect the Hounsfield measurements due to CT artifacts.

3. Hounsfield measurements of high-density materials have higher standard deviations, thus decreasing the value of Hounsfield measurement for differentiation of these materials.

4. Because of the existing number of dental restorative materials available, scanner and scan parameter dependence of the measurements and a variety of CT imaging artifacts, the identification (in contrast to differentiation) of dental materials is problematic.
Acknowledgments We thank our dental laboratory technicians Pascale Vitek and Marcel Baumann for their support and for preparing the lab side materials. Additionally, we thank our radiographer Dominic Gascho for his help in performing and evaluating the scans.

\section{References}

1. Kirchhoff S, Fischer F, Lindemaier G, Herzog P, Kirchhoff C, Becker C, et al. Is post-mortem CT of the dentition adequate for correct forensic identification?: Comparison of dental computed tomograpy and visual dental record. Int J Legal Med. 2008;122: 471-9.

2. Thali MJ, Markwalder T, Jackowski C, Sonnenschein M, Dirnhofer R. Dental CT imaging as a screening tool for dental profiling: advantages and limitations. J Forensic Sci. 2006;51:113-9.

3. Dirnhofer R, Jackowski C, Vock P, Potter K, Thali MJ. VIRTOPSY: minimally invasive, imaging-guided virtual autopsy. Radiogr Rev Publ Radiol Soc N Am Inc. 2006;26:1305-33.

4. Pittayapat P, Jacobs R, De Valck E, Vandermeulen D, Willems G. Forensic odontology in the disaster victim identification process. J Forensic Odontostomatol. 2012;30:1-12.

5. Baglivo M, Winklhofer S, Hatch GM, Ampanozi G, Thali MJ, Ruder TD. The rise of forensic and post-mortem radiologyanalysis of the literature between the year 2000 and 2011. J Forensic Radiol Imaging. 2013;1:3-9.

6. Coursey CA, Nelson RC, Boll DT, Paulson EK, Ho LM, Neville $\mathrm{AM}$, et al. Dual-energy multidetector CT: How does it work, what can it tell us, and when can we use it in abdominopelvic imaging. Radiographics. 2010;30:1037-55.

7. Ruder TD, Thali Y, Bolliger SA, Somaini-Mathier S, Thali MJ, Hatch GM, et al. Material differentiation in forensic radiology with single-source dual-energy computed tomography. Forensic Sci Med Pathol. 2013;9:163-9.

8. Jackowski C, Wyss M, Persson A, Classens M, Thali MJ, Lussi A. Ultra-high-resolution dual-source CT for forensic dental visualization-discrimination of ceramic and composite fillings. Int J Legal Med. 2008;122:301-7.

9. Ruder TD, Hatch GM, Ebert L, Thali Y, Allmendinger T, Schindera ST, et al. The forensic reference phantom-a new tool for quality assurance of attenuation measurements in forensic radiology. J Forensic Radiol Imaging. 2013;1:51-5.

10. Ruder TD, Thali Y, Schindera ST, Dalla Torre SA, Zech W-D, Thali MJ, et al. How reliable are Hounsfield-unit measurements in forensic radiology. Forensic Sci Int. 2012;220:219-23.

11. Van Dijken JW, Wing KR, Ruyter IE. An evaluation of the radiopacity of composite restorative materials used in Class I and Class II cavities. Acta Odontol Scand. 1989;47:401-7.

12. Barrett JF, Keat N. Artifacts in CT: recognition and avoidance. Radiogr Rev Publ Radiol Soc N Am Inc. 2004;24:1679-91. 